\title{
Diagnosis of neurofibromatosis type 1 - related pheocromocytoma after stroke and myocardial infarction
}

\author{
Ana Valea ${ }^{1,2}$, Andra Morar ${ }^{3}$, Adina Ghemigian ${ }^{4,5}$, Eugenia Petrova ${ }^{4,5}$, Claudiu Tupea ${ }^{4}$, \\ Mihaela Popescu ${ }^{6}$, Nicoleta Dumitru ${ }^{4}$, Mara Carsote ${ }^{4,5}$ \\ ${ }^{1}$ County Clinical Emergency Hospital, Cluj-Napoca, Romania \\ 2"Iuliu Hatieganu" University of Medicine and Pharmacy, Cluj-Napoca, Romania \\ 3"Leon Daniello" Clinical Pneumophthysiology Hospital, Cluj-Napoca, Romania \\ 4"C.I. Parhon" National Institute of Endocrinology, Bucharest, Romania \\ 5"Carol Davila" University of Medicine and Pharmacy, Bucharest, Romania \\ 'University of Medicine and Pharmacy, Craiova, Romania
}

\begin{abstract}
Hereditary syndromes underlying neuroendocrine tumours are extremely heterogeneous and, despite the genetic background, their recognition may actually be done later in life in many cases. Our purpose is to introduce a case of neurofibromatosis type 1 - related pheocromocytoma on a patient within his six decade of life after multiple cardiovascular complications. A 53-year old male is admitted for loss of appetite with weight loss, decreased exercise tolerance, transient occipital headache, night sweats. His medical history revealed arterial hypertension, right carotid artery ischemic stroke, and a recently non-STEMI myocardial infarction diagnosed two months ago. The pathological family history illustrated mother and a brother prematurely dying of myocardial infarction (no date of skin anomalies). Clinical examination reveals café-au-lait spots, axillary freckles, skin neurofibromas and a large plexiform neurofibroma in the right thigh. Evaluation of the adrenal gland revealed highly elevated values of urinary metanephrines and normetanephrines. Computed tomography showed a left adrenal gland tumour of $31 / 39 \mathrm{~mm}$. Thus neurofibromatosis type 1 in addition to a left pheocromocytoma was confirmed. A cardiologic examination before surgery was re-done. Given previous pathological history (cardiovascular events like stroke and nonSTEMI infarction) adrenalectomy was delayed for the moment in addition to second antiplatelet agent and the alpha blocker medication in increasing doses. The adrenal tumour removal is planned to be done as soon as cardiovascular risk is acceptable. The importance of endocrine check is seen in young patients with severe cardiovascular and neurological acute conditions that are actually caused by a hormonal excess like found in pheocromocytoma. Nevertheless, the spectrum of tumours associated with neurofibromatosis type 1 is heterogeneous and screening protocols are still a matter of debate. Delayed diagnosis worsts the overall prognosis.
\end{abstract}

Keywords: arterial hypertension, neurofibromatosis, adrenal tumour, pheocromocytoma

\section{INTRODUCTION}

Hereditary syndromes underlying neuroendocrine tumours are extremely heterogeneous and, despite the genetic background, their recognition may actually be done later in life $(1,2)$. The endocrine/neuroendocrine tumours that are found in relationship to genetic conditions varies from pituitary tumours to thyroid cancer or adrenal tumours or neuroendocrine neoplasia, frequently requiring a multi-disciplinary team $(3,4)$. Some of these tumours have a late onset thus they are detected due to associated hormonal production or due to local compressive symptoms/distant metastasis or they are detected by accident during a screening imaging procedure $(5,6,7)$. In this large field of hereditary syndromes, neurofibromatosis type 1 is an autosomal dominant condition caused by a muta- 
tion at the level of NF1 tumour supress gene (8). The skin hallmark is represented by café-au-lait spots, skinfold freckling as well as Lish nodules in addition to different forms of dermal neurofibromas $(1,8,9)$. Bone anomalies like scoliosis are positive in various combinations $(1,8,9)$. The associated tumour panel includes non-endocrine masses like optic gliomas, spinal neurofibromas, etc. and endocrine neoplasia like somatostatinoma or pheocromocytoma $(10,11)$.

\section{AIM}

Our purpose is to introduce a case of neurofibromatosis type 1 - related pheocromocytoma with late recognition during life after multiple cardiovascular complications are already diagnosed.

\section{METHOD}

This is a case report. The patient agreed for anonymously description of his medical records.

\section{CASE PRESENTATION}

A 53 - year old former smoker male was admitted for loss of appetite with weight loss $(10 \mathrm{~kg}$ within last 2-3 months), decreased physical exercise tolerance, transient occipital headache, night sweats, insomnia, low back pain and productive cough. His medical history revealed arterial hypertension, right carotid artery ischemic stroke, chronic obstructive pulmonary disease and a recently nonSTEMI myocardial infarction diagnosed two months ago. The pathological family history illustrated mother and a brother dying of myocardial infarction, two brothers with type 2 diabetes mellitus and father with Parkinson's disease. At admission, the patient was under treatment with ivabradine, conversion enzyme inhibitors, antiplatelet agents, lipid-lowering drugs, and bronchodilators.

The physical examination reveals: height of $165 \mathrm{~cm}$, weight of $53 \mathrm{~kg}$, BMI (Body Mass Index) of $19 \mathrm{~kg} / \mathrm{m}^{2}$, dysarthria, slightly elevated blood pressure, areas of hyperpigmented skin, café-aulait spots, axillary freckles, skin neurofibromas and a large plexiform neurofibroma in the right thigh (Figure 1,2).

Evaluation of the adrenal gland revealed elevated values of urinary metanephrines and normetanephrines, normal values of serum aldosterone and aldosterone-renin ratio, normal serum and urinary cortisol levels (Table 1).

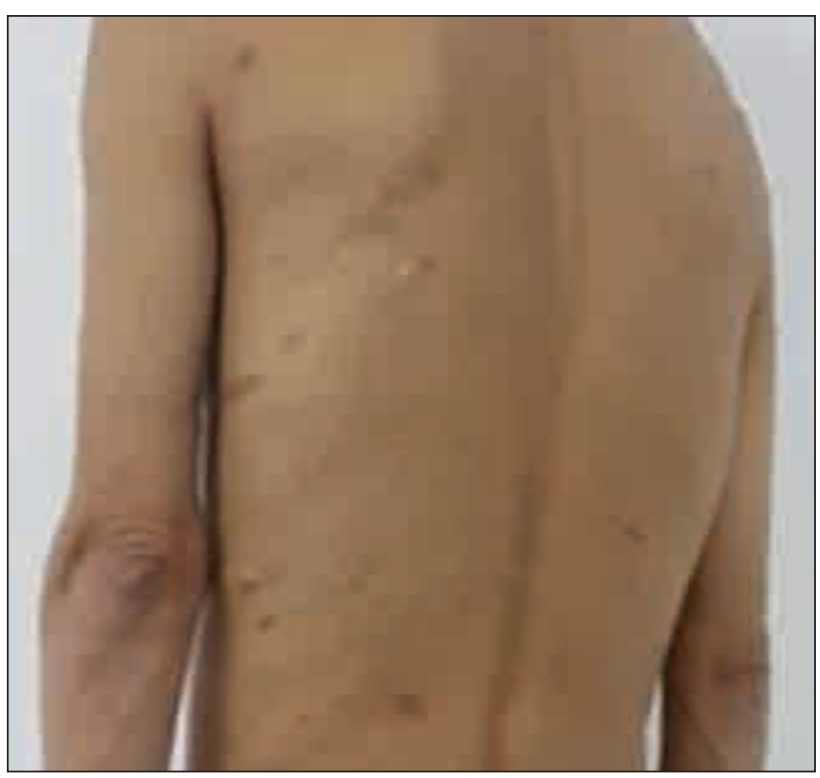

FIGURE 1. Café-au-lait spots and cutaneous neurofibromatosis in a 53-year-old man diagnosed with neurofibromatosis type 1 and pheochromocytoma

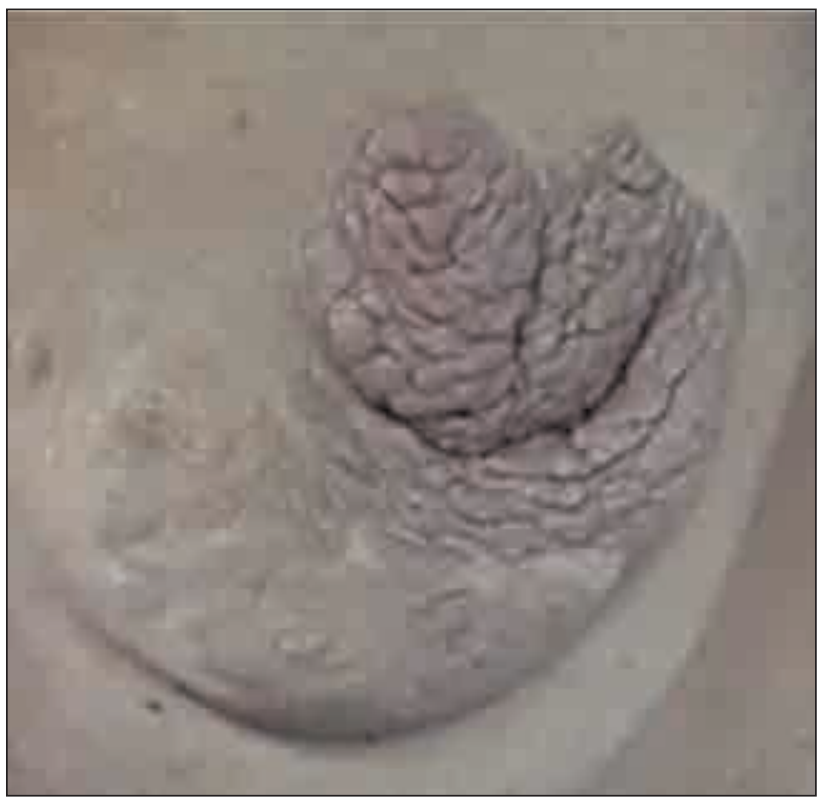

FIGURE 2. Plexiform neurofibroma in the right thigh in a 53-year-old man diagnosed with neurofibromatosis type 1 and pheochromocytoma and multiple cardiovascular complications

TABLE 1. Biochemical and hormonal profile of a 53-year old male with pheochromocytoma

\begin{tabular}{|l|c|c|c|}
\hline Parameter & $\begin{array}{c}\text { Patient's } \\
\text { value }\end{array}$ & $\begin{array}{c}\text { Normal } \\
\text { limits }\end{array}$ & Units \\
\hline Haemoglobin & 9.6 & $13-17$ & $\mathrm{~g} / \mathrm{dl}$ \\
\hline Haematocrit & 31.7 & $40-54$ & $\%$ \\
\hline Platelets & 882 & $150-400$ & $10^{\wedge} 9 / \mathrm{l}$ \\
\hline Leukocytes & 12.54 & $4-10$ & $10^{\wedge} 9 / \mathrm{l}$ \\
\hline Iron content & 9 & $70-180$ & $\mu \mathrm{g} / \mathrm{dl}$ \\
\hline Total cholesterol & 193 & $<200$ & $\mathrm{mg} / \mathrm{dl}$ \\
\hline Triglycerides & 77 & $<150$ & $\mathrm{mg} / \mathrm{dl}$ \\
\hline Total serum calcium & 9.12 & $8.8-10.6$ & $\mathrm{mg} / \mathrm{dl}$ \\
\hline lonic serum calcium & 4.69 & $4.4-5.4$ & $\mathrm{mg} / \mathrm{dl}$ \\
\hline
\end{tabular}




\begin{tabular}{|l|c|c|c|}
\hline Parameter & $\begin{array}{c}\text { Patient's } \\
\text { value }\end{array}$ & $\begin{array}{c}\text { Normal } \\
\text { limits }\end{array}$ & Units \\
\hline Urea & 45 & $17-43$ & $\mathrm{mg} / \mathrm{dl}$ \\
\hline $\begin{array}{l}\text { 24-hour urinary } \\
\text { metanephrines }\end{array}$ & $1,165.8$ & $59-394$ & $\mu \mathrm{g} / 24 \mathrm{~h}$ \\
\hline $\begin{array}{l}\text { 24-hour urinary } \\
\text { normetanephrines }\end{array}$ & $2,694.05$ & $128-934$ & $\mu \mathrm{g} / 24 \mathrm{~h}$ \\
\hline Plasma aldosterone & 2.75 & $1.17-23.6$ & $\mathrm{ng} / \mathrm{dl}$ \\
\hline $\begin{array}{l}\text { Aldosterone-renin } \\
\text { ra o }\end{array}$ & 0.04 & $<3.7$ & \\
\hline $\begin{array}{l}\text { Morning plasma } \\
\text { c ? }\end{array}$ & 17.51 & $6.4-22.8$ & $\mu \mathrm{g} / \mathrm{dl}$ \\
\hline $\begin{array}{l}\text { 24-hour free urinary } \\
\text { c ? }\end{array}$ & 3.96 & $1.5-63$ & $\mu \mathrm{g} / 24 \mathrm{~h}$ \\
\hline Parathormone & 47.6 & $12-88$ & $\mathrm{pg} / \mathrm{ml}$ \\
\hline Calcitonin & 8.4 & $0.5-18$ & $\mathrm{pg} / \mathrm{ml}$ \\
\hline TSH & 0.97 & $0.4-4$ & $\mu \mathrm{lU} / \mathrm{ml}$ \\
\hline FT4 & 1.04 & $0.61-1.35$ & $\mathrm{ng} / \mathrm{dl}$ \\
\hline
\end{tabular}

TSH = thyroid stimulating hormone; FT4 = free thyroxine; $\mu g=$ microgram $f L=$ femtoliters

The hormonal profile also indicated normal values for TSH (thyroid stimulating hormone), FT4 (free thyroxine), PTH (parathormone) and calcitonin (Table 1). Moreover, the assessments pointed slightly elevated carcinoembryonic antigen of $5.42 \mathrm{ng} / \mathrm{ml}$ (normal levels $<3 \mathrm{ng} / \mathrm{ml}$ ), iron deficiency related anaemia, leukocytosis and thrombocytosis (Table 1).

Thoracic-abdominal CT (computed tomography) angiography exam with contrast showed left lobe lung node of $16.8 \mathrm{~mm}$, normal right adrenal gland and an expansive formation in the left adrenal gland, inhomogeneous, with a non-uniform contrast uptake of 31/39 mm (Figure 3).

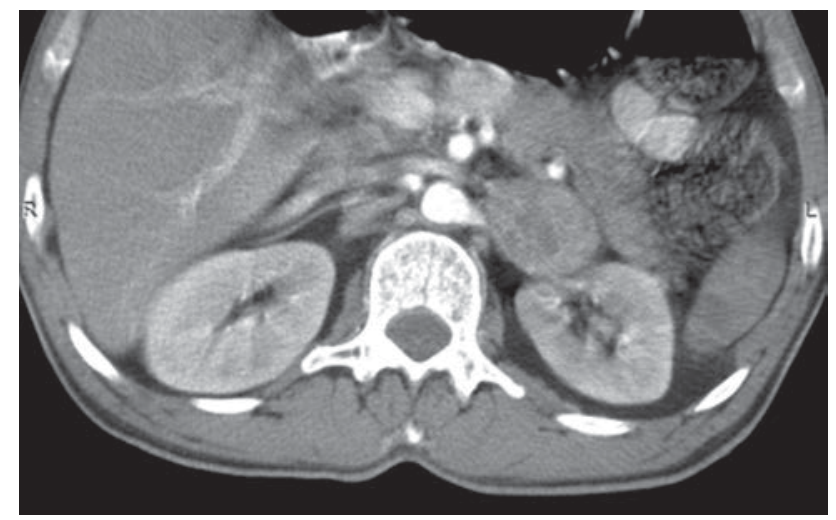

FIGURE 3. CT angiography exam with contrast in a patient diagnosed with pheochromocytoma show a tumour mass of $31 / 39 \mathrm{~mm}$ located in the right adrenal gland

Thus neurofibromatosis type 1 in addition to a left pheocromocytoma was confirmed. A cardiological examination before surgery was re-done. Given previous pathological history (cardiovascular events like stroke and nonSTEMI infarction) adrenalectomy was delayed for the moment in addition to second antiplatelet agent and the alpha blocker medication in increasing doses. The adrenal tumour removal is planned to be done as soon as cardiovascular risk is acceptable.

\section{DISCUSSIONS}

This case illustrates several practical aspects that we consider useful to be mentioned.

\section{Late diagnosis of a conditions with a genetic background}

The patient presents the association of some systemic diseases with potential for genetic transmission (like skin anomalies and pheocromocytoma) but with late diagnosis, at least in the case of type I neurofibromatosis, for which specific clinical hallmarks, such as café-au-lait spots and plexiform neurofibroma appeared before the age of 4 years $(12,13)$. For this patient, the diagnosis of type I neurofibromatosis was established based on the presence of 3 of the specific clinical elements, namely café-au-laits pots, axillary freckles, skin neurofibromas and plexiform neurofibroma in the right thigh (14). We do not have information about the presence of the disease among first-degree relatives but the death due to cardiovascular complications of his mother and one of his brothers is highly suggestive to a pheocromocytoma most probably related to neurofibromatosis type 1 (15). Neurofibromatosis type 1 (von Recklinghausen's disease) is an autosomal dominant disorder thus the genetic consulting of the entire family is needed (1).

\section{Neurofibromatosis type 1 and a pulmonary nodule}

The pulmonary nodule described on CT examination maybe an accidental association but also it be attributed to neurofibromatosis and related tumours, recognized for the $10 \%$ risk of mediastinal tumours $(16,17)$. Routine screening of lung conditions in this genetic syndrome is not implemented yet (18). A second neuroendocrine tumour may be positive under these circumstances as seen in other locations $(19,20)$. For instance, the NF1 gene mutations via signal transduction of $\mathrm{p} 21$, MAP or RAS pathways underlines a heterogeneous spectrum of abdominal tumours which is found in one out of four patients like gastrointestinal stromal tumours, neuroendocrine neoplasia, rhabdomyosarcoma (21). Nevertheless routine screening of 
these anomalies is not introduced in protocols of neurofibromatosis type 1 but specialised multidisciplinary teams should follow the subjects in any medical and surgical area (22). In this particular case, serial imagery is needed for the follow-up of the nodule since biopsy or other potential traumatic interventions are less feasible due to active pheocromocytoma at this point.

\section{Pheocromocytoma and neurofibromatosis type 1}

The association with pheochromocytoma is mentioned in $2 \%$ (varying from 1 to $5.7 \%$ ) of cases as oppose to general population (of less than 1\%) $(23,24)$. As of this patient, the pheochromocytoma usually has a unilateral location (25). Delaying the recognition of catecholamines producing tumour is dramatic due to negative effects on cardiovascular and neurological status as seen here, even causing cardiac arrest, sudden death or premature death thus adrenalectomy is needed as soon as possible even in bilateral tumours (26). As seen in other tumours that were mentioned before, the screening of pheocromocytoma in families with the NF1 gene mutation is less established in guidelines even it seems extremely useful (25). In this case we have the first information about high blood pressure values from the age of 43 years. Screening for pheochromocytoma was performed in the context of the association of arterial hypertension in young age complicated with ischemic stroke that occurred 4 years after the onset of hypertension. The high cardiovascular risk for ischemic events is also supported by recent myocardial infarction and suggestive family medical background. Other adrenal tumours causing massive cardiovascular damage includes Cushing's syndrome and Conn's syndrome (27,28). Elevated blood pressure due to endocrine tumours in young patients is also caused by pituitary tumours like somatotropinoma or corticotropinoma $(29,30)$. Moreover, thyrotoxicosis or even hypercalcemia (but parathyrin secreting tumours are more frequent in females) may be associated with arterial hypetension $(31,32)$.

\section{Other aspects}

The normal ultrasound appearance of the thyroid, normal values of calcitonin, PTH and calcemia excluded other multiple neoplasia syndromes in this particular case but their routine endocrine evaluation is necessary (33). In order to have an adequate preoperative approach and to control blood pressure values, alpha blocker medication was included in the therapeutic scheme. Based on cardiologist evaluation, the surgery was delayed for the moment in addition to new medication but adrenalectomy is needed since excessive levels of metanephrines/normetanephrines worse the cardiovascular status. Associated thrombocytosis is an additional risk factor for ischemic phenomena $(34,35)$. Also, iron deficiency - related anaemia which seems of unknown cause, probably as a sign of chronic illness. Thrombocytosis is mostly caused by other amines that are produced by pheocromocytoma apart for catecholamines, knowing the complex cocktail of molecules produced by such tumours similar to neuroendocrine neoplasia $(34,35)$. Surgical removal of adrenal tumour secreting catecholamines has a curative effect but complex cardiovascular medication is needed before, during, and after surgery $(36,37)$. However, the risk of other cardiac and neurological emergences is very high (38). Therefore close endocrine, cardiac, neurological, biochemical, and imagery check-up is recommended.

\section{CONCLUSIONS}

The importance of endocrine check is related to young patients with severe cardiovascular and neurological acute conditions that are actually caused by a hormonal excess like seen in pheocromocytoma. Nevertheless, the spectrum of endocrine and non-endocrine tumours associated with neurofibromatosis type 1 is heterogeneous and screening protocols are still a matter of debate.

\section{Acknowledgement}

We thank each member of the medical teams and the patient.

Conflict of interest: none declared Financial support: none declared

\section{REFERENCES}

1. Lewis MA. Hereditary Syndromes in Neuroendocrine Tumors. Curr Treat Options Oncol. 2020;21(6):50.

2. Poiana C, Carsote M, Ardeleanu C, Terzea D, Avramescu ET, Neamtu MC, Danciulescu Miulescu R. The value of the immunohistochemistry in a case of gastric neuroendocrine tumor and thyroid metastasis, Rom J Morphol Embryol. 2011;52(1):187-192.

3. Anderson JL, Gutmann DH. Neurofibromatosis type 1. Handb Clin Neurol. 2015;132:75-86.

4. Poiana C, Neamtu MC, Avramescu ET, Carsote M, Trifanescu R, Terzea D, Neamtu OM, Ferechide D, Danciulescu Miulescu R. The poor prognosis factors in G2 neuroendocrine tumor. Rom J Morphol Embryol. 2013;54(3 Suppl):717-720. 
5. Gheorghisan-Galateanu AA, Carsote C, Valea A. Incidentaloma: from general practice to specific endocrine frame. JPMA. The Journal of the Pakistan Medical Association. 2017; 67(6):917-922.

6. Carsote M, Chirita C, Dumitrascu A, Hortopan D, Fica S, Poiana C. Pituitary incidentalomas-how often is too often?. Journal of Medicine and Life. 2009;2(1):92-97.

7. Carsote M, Valea A, Dumitru N, Terzea D, Petrova E, Albu S, Buruiana A, Ghemigian A. Metastases in daily endocrine practice. Archives of Balkan Medical Union. 2016;51(4):476-480.

8. Rosenbaum T, Wimmer K. Neurofibromatosis type 1 (NF1) and associated tumors. Klin Padiatr. 2014;226(6-7):309-15.

9. Carsote M, Paun S, Neamtu MC, Avramescu ET, losif C, Terzea D, Constantinoiu S, Danciulescu Miulescu R, Neamtu OM, Poiana C. The immunohistochemistry aspects in two cases of neurofibromatosis-associated abdominal tumors, Rom Journal Morphol Embryol. 2012;53(2):401-405.

10. Poiana C, Neamtu MC, Avramescu ET, Carsote M, Trifanescu R, Terzea D, Neamtu OM, Danciulescu Miulescu R. The dedifferentiation of neuroendocrine tumor metastases: myth or reality? J Morphol Embryol. 2013;54(1):201-203.

11. Poiana C, Carsote M, Baloescu R, Stanescu B, Petrescu R, Corneci C, Hortopan D, Chirita C, loachim D, Terzea D. The adrenalectomy in rare endocrine tumors - two cases report. Journal of Surgery (Jurnalul de Chirurgie lasi). 2010;6(1):47-53.

12. Miller DT, Freedenberg D, Schorry E, Ullrich NJ, Viskochil D, Korf BR. Health Supervision for Children With NeurofibromatosisType 1. Pediatrics. 2019;143(5):e20190660.

13. Ho TH, Lee JT, Liu TC, Lin JC, Yang FC. Neurofibromatosis type 1. QJM. 2019;112(4):307.

14. Cimino PJ, Gutmann DH. Neurofibromatosistype 1. Handb Clin Neurol. 2018;148:799-811.

15. Hirbe AC, Gutmann DH. Neurofibromatosis type 1: a multidisciplinary approach to care. Lancet Neurol. 2014;13(8):834-43.

16. Jutant E-M, Girerd B, Jaïs X, Savale L, O'Connell C, Perros F, Sitbon $\mathrm{O}$, Humbert M, Montani D. Pulmonary hypertension associated with neurofibromatosis type 1. Eur Respir Rev. 2018;27(149):180053.

17. Carsote M, Ghemigian A, Terzea D, Gheorghisan-Galateanu AA, Valea A. Cystic adrenal lesions: focus on pediatric population (a review). Clujul Medical. 2017;90(1):5-12.

18. Dehal N, Arce Gastelum A, Millner PG. Neurofibromatosis-Associated Diffuse Lung Disease: A Case Report and Review of the Literature. Cureus. 2020;12(6):e8916.

19. Sandru F, Carsote M, Valea A, Albu SE, Petca RC, Dumitrascu MC. Somatostatinoma: Beyond neurofibromatosis type 1 (Review). Exp Ther Med. 2020;20(4):3383-338.

20. Poiana C, Carsote M, Chirita C, Terzea D, Paun S, Beuran M. Giant adrenal cyst: case study. J Med Life. 2010;3(3):308-313.

21. Dare AJ, Gupta AA, Thipphavong S, Miettinen M, Gladdy RA. Abdominal neoplastic manifestations of neurofibromatosis type 1. Neurooncol Adv. 2020;2(Suppl 1):i124-i133.

22. Ly KI, Blakeley JO. The Diagnosis and Management of Neurofibromatosis Type 1. Med Clin North Am. 2019;103(6):10351054.

23. Hari Kumar KVS, Shaikh A, Sandhu AS, Prusty P. Neurofibromatosis 1 with pheochromocytoma. Indian J Endocrinol Metab. 2011; 15(Suppl4):S406-S408.
24. Zafara W, Chaucera B, Davalosa F, Beenisha S, Chevenona M, Nfonoyima J. Neurofibromatosis Type 1 With a Pheochromocytoma: A Rare Presentation of Von Recklinghausen Disease. Journal of Endocrinology and Metabolism 2015;5(5):309-311.

25. Tate JM, Gyorffy JB, Colbum JA. The importance of pheochromocytoma case detection in patients with neurofibromatosis type 1: A case report and review of literature. SAGE Open Medical Case Reports. 2017;5:1-4.

26. Albu SE, Carsote M, Capatina C, Dumitrascu A, Ghemigian A. Adrenal surgical approach in a women with synchronous bilateral adrenal tumours. Journal of Surgical Sciences. 2015;2(3):132-135.

27. Poiana C, Chirita C, Carsote M, Hortopan H, loachim D, Corneci CM, Stanescu B. Adrenal and pituitary incidentalomas in a case of Cushing's syndrome. Chirurgia (Bucharest). 2013; 1990:108(6):886-891.

28. Gheorghiu ML, Hortopan D, Dumitrascu A, Caragheorgheopol A, Stefanescu A, Trifanescu R, Niculescu D, Baciu I, Carsote M, Poiana C, Badiu C, Coculescu M. Age-related endocrine tumors: Nonfunctioning adrenal tumors as compared to pituitary adenomas. Acta Endocrinologica-Bucharest. 2009;5(3):371-383.

29. Valea A, Carsote M, Ghervan C, Georgescu C. Glycemic profile in patients with acromegaly treated with somatostatin analogue. Journal of Medicine and Life. 2015;8(Spec Issue):82-6.

30. Valea A, Ghervan C, Carsote M, Morar A, lacob I, Tomesc F, Pop DD, Georgescu C. Effects of combination therapy: somatostatin analogues and dopamine agonists on GH and IGF1 levels in acromegaly. Clujul Medical. 2015;88(3):310-17.

31. Trifanescu R, Danciulescu Miulescu R, Carsote M, Poiana C. Hypokalemic periodic paralysis as first sign of thyrotoxicosis. $J$ Med Life. 2013;15:6(1):72-75.

32. Radu L, Carsote M, Gheorghisan-Galateanu AA, Preda SA, Calborean V, Stanescu R, Gheorman V, Albulescu DM. Blood Parathyrin and Mineral Metabolism Dynamics A clinical analyze. Rev. Chim. (Bucharest). 2018;69(10):2754-8.

33. Dumitru N, Ghemigian A, Carsote M, Albu SE, Terzea D, Valea A. Thyroid nodules after initial evaluation by primary health care practitioners: an ultrasound pictorial essay. Archives of the Balkan Medical Union. 2016;51(3):434-8.

34. Petr EJ, Else T. Pheochromocytoma and Paraganglioma in Neurofibromatosis type 1: frequent surgeries and cardiovascular crises indicate the need for screening. Clinical Diabetes and Endocrinology. 2018; 4:1-5.

35. Carsote M, Radoi V, Geleriu A, Mihai A, Ferechide S, Opris D, Paun $\mathrm{D}$, Poiana C. The serotonin and the bone assessment. Journal of Medicine and Life. 2013;6(2):151-155.

36. Luis-García C, Arbonés-Aran E, Teixell-Aleu C, Lorente-Poch L, Trillo-Urrutia L. Clevidipine for hypertension treatment in pheochromocytoma surgery. RevEsp Anestesiol Reanim. 2018;65(4):225-228.

37. Fermandois M, Altamirano J, Rojas F, Román C, Pinto I. Perioperative management of paragangliomas and pheochromocytomas. Medwave. 2020;20(2):e7830.

38. Muratori D, Pedrotti P, Baroni M, Belloni A, Quattrocchi G, Milazzo A, Giannattasio C, Roghi A. Catecholamine-induced myocarditis in pheochromocytoma. G Ital Cardiol (Rome). 2017;18(2):164-168. 